\title{
Clinical Findings and Results of Surgical Resection in 19 Cases of Spinal Osteoid Osteoma
}

\author{
Mohammad Reza Etemadifar, Abdollah Hadi \\ Orthopedic Surgery Department, Alzahra Educational Hospital, Isfahan University of Medical Sciences, Isfahan, Iran
}

\section{Study Design: Descriptive cases series.}

Purpose: To evaluate clinical findings and results of conventional surgery in patients with spinal osteoid osteoma (00).

Overview of Literature: 00 is a rare benign tumor with spinal involvement rate of about $10 \%-20 \%$.

Methods: This descriptive study was conducted on 19 patients (11 males and 8 females with an average age of 19.8 years) with documented histopathological and imaging findings of 00 referred to a university hospital. Neurologic symptoms and pain were scored before and after the open surgical excision. Data were analyzed by SPSS ver. 16 software using chi-square and significance level of 0.05 .

Results: The most common complaint was back or neck pain (84.2\%) and in 68.4\% spinal deformity (mostly scoliosis) shown with an average cobb angle of $21^{\circ}$ at presentation. The sites of involvement were $35 \%$ in the lumbar, $35 \%$ in the thoracic, $25 \%$ in the cervi$\mathrm{cal}$, and $5 \%$ in the sacrum. Lamina was the most common site $(50 \%)$ of involvement with predilection for the right side $(p=0.001)$. All patients were treated by conventional surgical excision with a complete recovery of pain and deformity. No recurrence occurred after a mean follow up of 44.5 months, but 4 of 19 cases instrumented because of induced instability. In one case there were two levels of involvement (C7-T1) simultaneously. Interestingly, 10 out of 19 of our cases belonged to a specific race (Bakhtiari).

Conclusions: Surgical intra-lesional curettage is potentially an effective method without any recurrence, which can lead to spontaneous scoliosis recovery and pain relief. Race may be a potential risk factor for spinal (00).

Keywords: Osteoid osteoma; Bone tumor; Surgical outcoms; Spine

\section{Introduction}

Osteoid osteoma $(\mathrm{OO})$ is a primary benign bone lesion that was first described by Jaffe [1] in 1935 . He has again proposed the new term of benign osteoblastoma in 1956 [2].

OO accounts contributes for approximately $12 \%$ of benign skeletal neoplasms arising in the cortical bone especially in long bones, and spinal involvement of $10 \%-20 \%$. In some papers up to $40 \%$ spinal involvement has been reported $[3,4]$.

It can develop in any area of spinal column but, mainly involves the lumbar spine with predilection for posterior elements in $75 \%$ of cases especially lamina or sectors of 2-4 and 9-11 in Weinstein-Boriani-Biagini (WBB) classification (Fig. 1) [5,6]. Pars interarticularis is the most common (73\%) site of involvement [5].

Most of the cases occur in the second decade of age, but variation spans from the first to fourth decade with a male to female predominance of $2: 1[7,8]$.

Received Sep 29, 2014; Revised Nov 13, 2014; Accepted Nov 25, 2014

Corresponding author: Abdollah Hadi

Orthopedic Surgery Department, Alzahra Educational Hospital, Isfahan University of Medical Sciences,

Isfahan 8174675731, Iran

Tel: +98-3136255555, Fax: +98-3136692174, E-mail: dr.hadi74@yahoo.com 
Although it was claimed that $\mathrm{OO}$ is a solitary lesion, there is some evidence that shows the possibility of multilevel involvement in this tumor. As we reported previously two level involvements were seen in an 18 years old boy (Fig. 2) [9].

The most common clinical symptom reported is (night) pain (up to $80 \%-100 \%$ ), which is induced by nidus prostaglandin/prostacyclin production [10-12].

Painful scoliosis is a common presentation $(63 \%-70 \%)$ of spinal OO [13] which is due to soft tissue and muscle irritation and finally induced asymmetrical spasm [14].

Plain X-rays are not usually sufficient to determine the lesion, but Technetium-99 bone scan remains the most sensitive tool for localization with only one reported false negative in the literature [15].

Computed tomography (CT) scan, magnetic resonance imaging (not always indicated) and recently (Technetium-99m methylene diphosphonate single- photon

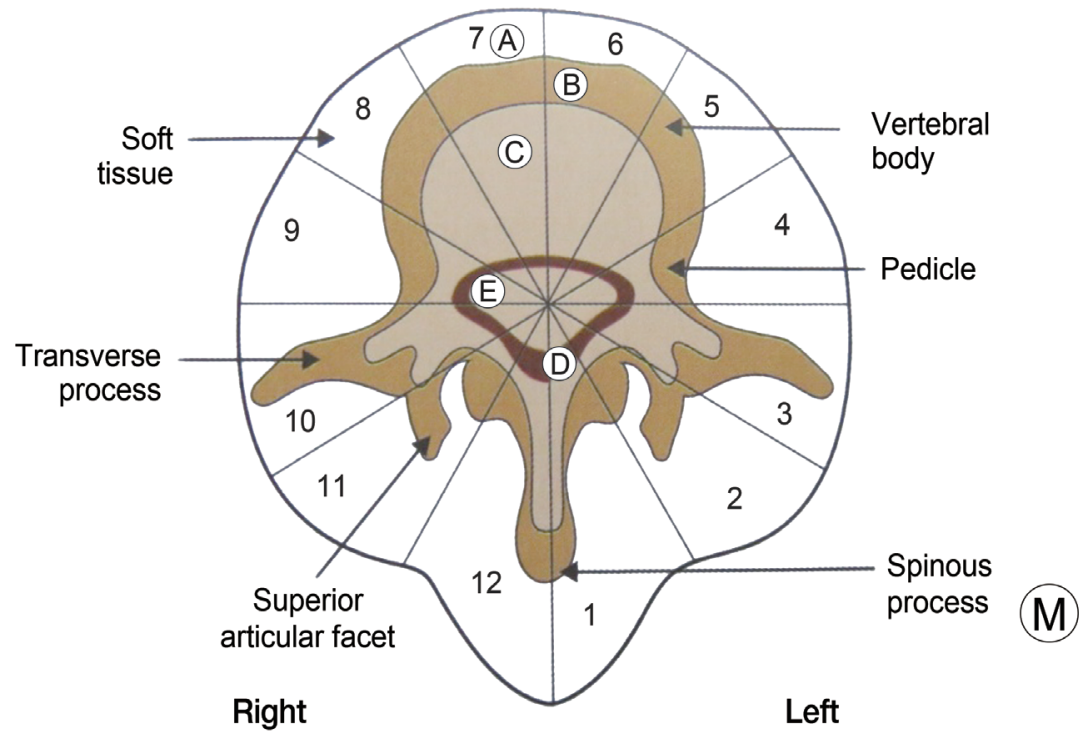

Fig. 1. Weinstein-Boriani-Biagini (WBB) staging of the spine tumor. Sector 2-4, 35\%; Sector 5-8, 5\%; Sector 9-11, 60\%; Sector 1-12, 0\%. Reprinted from Eck and DiPaola [6].
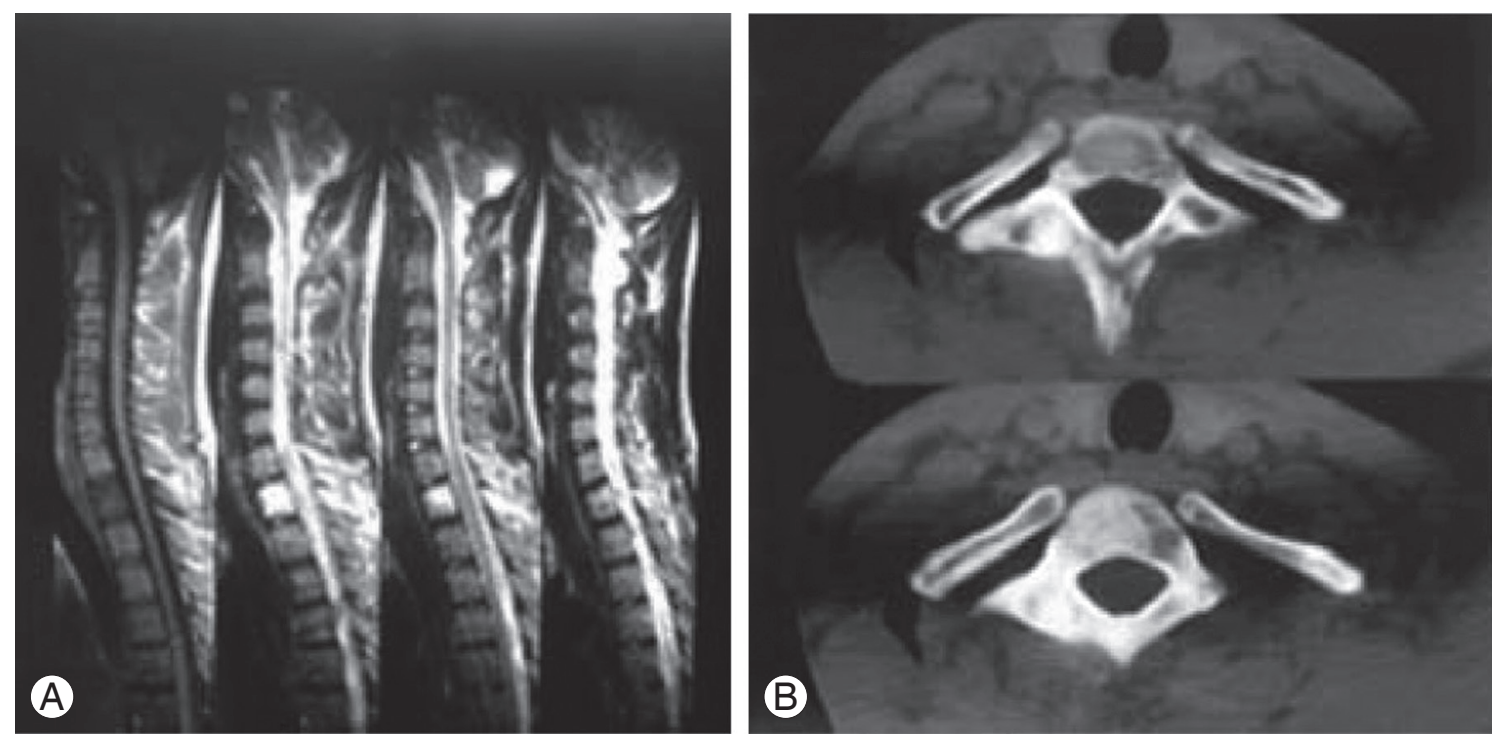

Fig. 2. (A, B) Our case report 2005, C7 and T1 osteoid osteoma simultaneously. 
emission tomography/CT) scan have great value for both diagnostic and therapeutic considerations [16-18] (Fig. 3).

Conventionally, medical treatment of pain has been considered the first management option in OO. Positive response to nonsteroidal anti-inflammatory drugs especially aspirin is reported in $14 \%-90 \%$ of cases $[12,19]$.

Surgery is the most common definitive method of treatment for spinal $\mathrm{OO}$ with a good prognosis for pain relief if total nidus excision could be done. Accepted indications for surgery are persistent pain or spinal deformity and rarely, neural deficit $[20,21]$.

Recently percutaneous radiofrequency thermal ablation and laser coagulation have been introduced as a minimally invasive treatment and is supported by some literature [22-24].

The aim of our study was to review the results of treatment of spinal OO cases from 2004 to 2012. The study describes clinical findings and outcomes of conventional open surgery in this case series.

\section{Materials and Methods}

For the purpose of this study, 19 patients (20 vertebral lesions) were retrospectively evaluated after confirmation by the of Isfahan University of Medical Sciences ethnic committee.

The office charts and hospital files from orthopedic spinal surgery and neurosurgery departments were evaluated first. All available data for all patients (from 3 surgeons) with histopathologically confirmed diagnosis of $\mathrm{OO}$ from February 2004 to August 2012 that underwent surgical treatment, were collected. Hospital history and physical examination reports, imaging findings, operative room notes and finally office follow up notes were reviewed for assessment and analysis.

Exclusion criteria included any pathologic report except $\mathrm{OO}$ and CT scan nidus size $>1.5 \mathrm{~cm}$.

Pain and scoliosis and their relevant parameters were especially mentioned and evaluated. Data were analyzed by SPSS ver. 16 (SPSS Inc., Chicago, IL, USA) software using descriptive statistics, frequency distribution and chisquare test (considering significance level as $p<0.05$ ).

\section{Results}

There were 19 cases operated by conventional open surgery. The average follow up length was 44.5 months (range, 9-115 months).

One of our cases had two levels of OOs (C7 and T1), that presented as a case report previously [9].

There were 11 males (58\%) and 8 females (42\%) with a mean age of 19.8 years (range, 8-38 years) (Table 1$)$. Our findings are presented in Tables 1-6.

The most important complaint was pain in 16 of 19 cases $(84.2 \%)$. Only 7 patients had radicular pain pattern (37\%). Temporally pain relief with aspirin was detected in
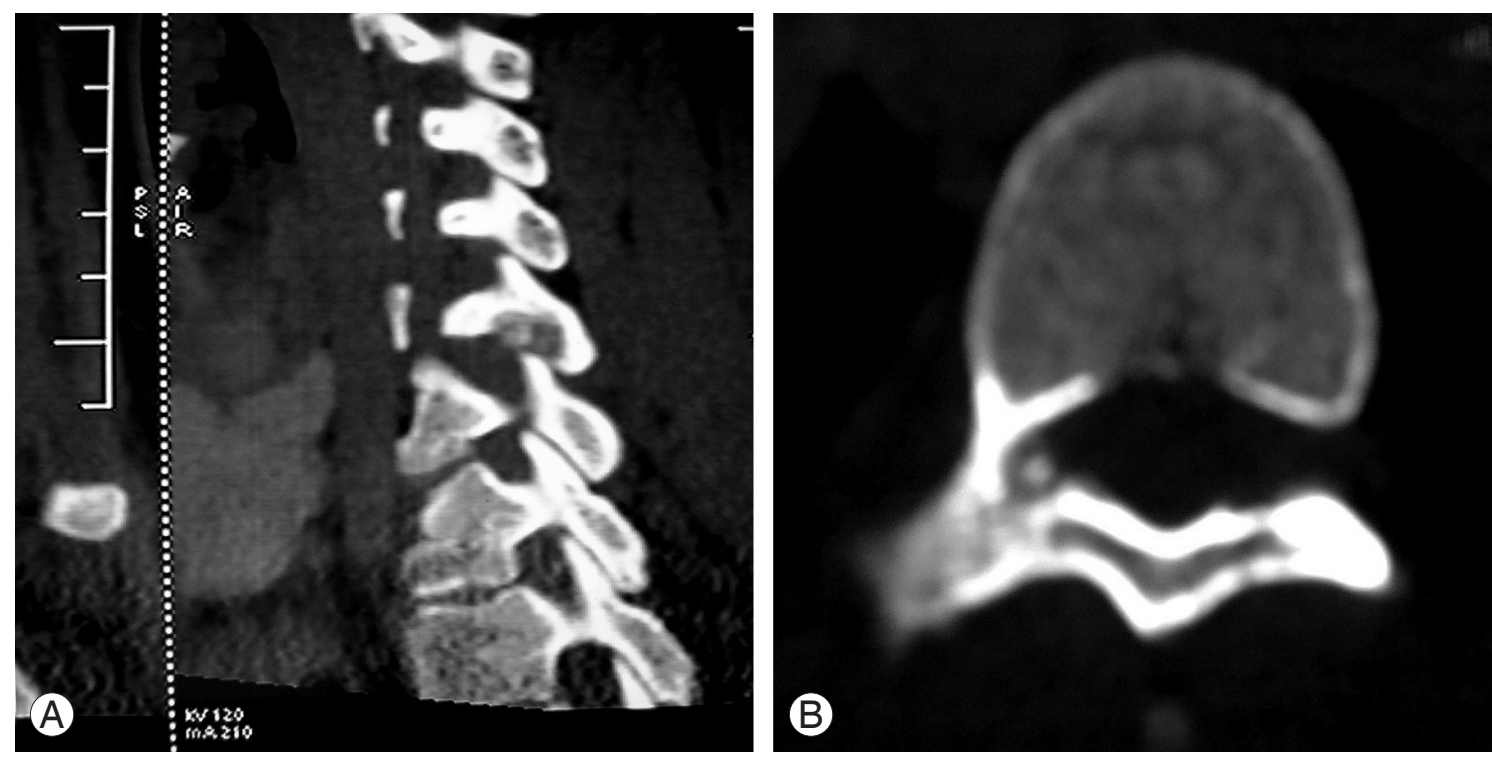

Fig. 3. (A, B) C6 and L3 osteoid osteoma. 
Table 1. Information about the patients suffering from spinal osteoid ostoma

\begin{tabular}{|c|c|c|c|c|c|c|c|c|c|}
\hline \multirow[b]{2}{*}{ No. } & \multirow[b]{2}{*}{$\begin{array}{l}\text { Age } \\
\text { (yr) }\end{array}$} & \multirow[b]{2}{*}{ Gender } & \multirow[b]{2}{*}{$\begin{array}{c}\text { Duration of } \\
\text { symptom (mo) }\end{array}$} & \multirow[b]{2}{*}{ Pain } & \multirow[b]{2}{*}{$\begin{array}{l}\text { Nocturnal } \\
\text { pain }\end{array}$} & \multirow[b]{2}{*}{ Radiculopathy } & \multirow[b]{2}{*}{$\begin{array}{l}\text { Response } \\
\text { to ASA }\end{array}$} & \multicolumn{2}{|c|}{ Deformity } \\
\hline & & & & & & & & $\begin{array}{c}\text { Scoliosis } \\
\left({ }^{\circ}\right)\end{array}$ & $\begin{array}{c}\text { Torticollis } \\
\left({ }^{\circ}\right)\end{array}$ \\
\hline 1 & $18^{\text {a) }}$ & Male & 36 & + & + & - & + & - & 15 \\
\hline 2 & 12 & Male & 7 & + & - & - & - & 18 & - \\
\hline 3 & 26 & Female & 52 & + & + & + & + & 22 & - \\
\hline 4 & 20 & Male & 8 & + & - & - & - & 20 & - \\
\hline 5 & 23 & Male & 9 & + & - & + & + & 15 & - \\
\hline 6 & 22 & Female & 5 & + & + & + & - & - & - \\
\hline 7 & 15 & Male & 5 & - & - & - & - & 25 & - \\
\hline 8 & 33 & Male & 25 & + & + & + & - & - & - \\
\hline 9 & 23 & Male & 56 & + & - & - & + & - & - \\
\hline 10 & 24 & Male & 6 & + & - & - & + & - & - \\
\hline 11 & 22 & Male & 10 & - & - & - & - & 23 & - \\
\hline 12 & $13^{\mathrm{b})}$ & Female & 9 & + & + & - & - & 36 & - \\
\hline 13 & 8 & Female & 8 & - & - & - & - & 25 & - \\
\hline 14 & 23 & Male & 6 & + & + & + & + & - & - \\
\hline 15 & 23 & Male & 4 & + & + & - & - & 24 & - \\
\hline 16 & 13 & Female & 5 & + & - & + & - & 18 & - \\
\hline 17 & 10 & Female & 11 & + & + & - & + & 22 & - \\
\hline 18 & 15 & Female & 18 & + & + & - & - & - & - \\
\hline 19 & 34 & Female & 7 & + & + & - & - & 10 & - \\
\hline
\end{tabular}

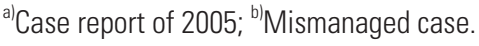

7 of 16 cases $(44 \%)$.

Coronal deformities including scoliosis and torticollis were detected in 13 of 19 cases (68.5\%) with an average Cobb angle of $21^{\circ}$ (range, $10^{\circ}-36^{\circ}$ ). Only 3 of 13 cases (23\%) with coronal deformities had no or very light pain (visual analogue scale $[\mathrm{VAS}]<4$ ). There was no case with neural deficit (Table 2).

Although there were more cases in the lumbar and thoracic regions, there was no statistically significant difference between different regions of the spine $(p>0.05)$ (Table 3).

The most common location for vertebral lesion was the lamina (including pars interarticularis) and the least location was the spinous process (chi square test, $p=0.001$ ) (Table 4).

Considering WBB classification, there was statistically a significant difference between the sectors $(p<0.001)$ with, more preponderance for the right side (Table 5).

All of the patients were treated by open intra-lesional excision, 18 cases with the posterior and one with the anterior approaches.

Overall, in four cases, instrumentation and fusion were done. Two cases due to facet resection, one due to anterior corpectomy and the last one due to misdiagnos. The misdiagnosed case (Tables 1, 2; No. 12) was a 13-year-old girl with a previous ( 9 months before presentation) history of trauma whose painful curve was treated as an "idiopathic and progressive scoliosis". But in subsequent follow-ups, L3 OO was recognized as a true diagnosis and finally reoperation was done. This case had the biggest curve in our patients with $36^{\circ} \mathrm{Cobb}$ angle. In all cases (except the misdiagnosed patient) pain dramatically disappeared within an average of 1.6 days (range, 1-6 days). No recurrence was found in our final follow ups (Table 6).

Our single complication was in the misdiagnosed patient with hook dislodgement that required surgery for the third time and revision. 
Table 2. Pathological locations and the lesions features

\begin{tabular}{|c|c|c|c|c|c|c|c|c|c|c|}
\hline No. & $\begin{array}{l}\text { Location in } \\
\text { column }\end{array}$ & $\begin{array}{l}\text { Location in } \\
\text { vertebrae }\end{array}$ & $\begin{array}{l}\text { Sectors } \\
\text { of WBB }\end{array}$ & $\begin{array}{l}\text { No. of } \\
\text { level }\end{array}$ & $\begin{array}{l}\text { Frankle } \\
\text { scale }\end{array}$ & $\begin{array}{l}\text { Post op } \\
\text { instability }\end{array}$ & $\begin{array}{c}\text { Need to } \\
\text { instrument }\end{array}$ & Approach & Recurrence & $\begin{array}{l}\text { Follow- } \\
\text { up (mo) }\end{array}$ \\
\hline 1 & $\mathrm{C7}, \mathrm{T1}^{\mathrm{a})}$ & Lamina & $9-11$ & 2 & $E$ & - & - & $\mathrm{P}$ & - & 115 \\
\hline 2 & L5 & Lamina & $2-4$ & 1 & E & - & - & $P$ & - & 13 \\
\hline 3 & L3 & Pedicle & $2-4$ & 1 & $E$ & - & - & $P$ & - & 21 \\
\hline 4 & T8 & Lamina & $9-11$ & 1 & E & - & - & $P$ & - & 18 \\
\hline 5 & T11 & Pedicle & $2-4$ & 1 & E & - & - & $P$ & - & 36 \\
\hline 6 & C6 & Lamina & $9-11$ & 1 & E & - & - & $P$ & - & 22 \\
\hline 7 & $\mathrm{~T} 10$ & Facet & $2-4$ & 1 & $E$ & + & + & $\mathrm{P}$ & - & 9 \\
\hline 8 & L4 & Lamina & $9-11$ & 1 & E & - & - & $P$ & - & 11 \\
\hline 9 & C4 & Body & $5-8$ & 1 & $E$ & + & + & A & - & 14 \\
\hline 10 & $\mathrm{~T} 11$ & Pedicle & $2-4$ & 1 & $E$ & - & - & $P$ & - & 84 \\
\hline 11 & $\mathrm{~T} 11$ & Pedicle & $9-11$ & 1 & $E$ & - & - & $P$ & - & 96 \\
\hline 12 & $\left\lfloor 3^{b)}\right.$ & Lamina & $9-11$ & 1 & $E$ & - & + & $\mathrm{P}$ & - & 45 \\
\hline 13 & L3 & Facet & $9-11$ & 1 & $E$ & + & + & $\mathrm{P}$ & - & 40 \\
\hline 14 & C5 & Facet & $9-11$ & 1 & E & - & - & $P$ & - & 35 \\
\hline 15 & $\mathrm{~T} 12$ & Lamina & $9-11$ & 1 & E & - & - & $P$ & - & 52 \\
\hline 16 & L4 & Facet & $2-4$ & 1 & E & + & + & $P$ & - & 95 \\
\hline 17 & L4 & Pedicle & $9-11$ & 1 & $\mathrm{E}$ & - & - & P & - & 53 \\
\hline 18 & C5 & Lamina & $9-11$ & 1 & E & - & - & P & - & 69 \\
\hline 19 & S1 & Lamina & $2-4$ & 1 & $\mathrm{E}$ & - & - & $P$ & - & 17 \\
\hline
\end{tabular}

WBB, Weinstein-Biagini-Boriani; P, posterior; A, anterior.

${ }^{a}$ Case report of 2005; ${ }^{\text {bl}}$ Mismanaged case.

Table 3. Position of lesions in spinal column

\begin{tabular}{llcccc} 
Region & \multicolumn{1}{c}{ Level } & No. of sites & Percent (\%) & $\begin{array}{c}\text { The most } \\
\text { common site(s) }\end{array}$ & C5 \\
Cervical & C4-C5-C5-C6-C7 & 5 & 25 & T11 & 0.089 \\
Thoracic & T1-T8-T10-T11-T11-T11-T12 & 7 & 35 & L3-L4 \\
Umbar & L3-L3-L3-L4-L4-L4-L5 & 7 & 35 & S1 \\
\hline Sacrum & S1 & 1 & 5 & \\
\hline
\end{tabular}

Table 4. Position of lesion in the vertebrae

\begin{tabular}{lccc} 
Region & No. & Total (\%) & $p$-value \\
Lamina & RT, 8; LT, 2 & $10(50)$ & 0.001 \\
Pedicle & RT, 2; LT, 3 & $5(25)$ & \\
Facet & RT, 2; LT, 2 & $4(20)$ & \\
Body & 1 & $1(5)$ & \\
Spinous process & 0 & 0 & \\
\hline
\end{tabular}

$\mathrm{RT}$, right; Lt, left.
Table 5. Position of lesions by the classification of WBB

\begin{tabular}{llcc} 
Sector & Anatomic location & No. $(\%)$ & $p$-value \\
$2-4$ & Left L-P-TP & $7(35)$ & $<0.001$ \\
$9-11$ & Right L-P-TP & $12(60)$ & \\
$12-1$ & Spinous process & - & \\
$5-8$ & Body & $1(5)$ & \\
\hline
\end{tabular}

WBB, Weinstein-Biagini-Borianik; L, lamina; P, pedicle; TP, transverse process. 
Table 6. Spine deformity behavior status

\begin{tabular}{lccccccc} 
Type & No. $(\%)$ & $\begin{array}{c}\text { Average } \\
\text { angle }\left({ }^{\circ}\right)\end{array}$ & $\begin{array}{c}\text { Range } \\
\left({ }^{\circ}\right)\end{array}$ & $\begin{array}{c}\text { Pain free } \\
\text { (case) }\end{array}$ & Side of nidus & $\begin{array}{c}\text { Spontaneous } \\
\text { resolution }\end{array}$ & $\begin{array}{c}\text { Average duration } \\
\text { of recovery }\end{array}$ \\
Scoliosis & $12(60)$ & 21.5 & $10-36$ & 3 & In concave & Yes for all & $8 \mathrm{mo}$ \\
Torticollis & $1(5)$ & 15 & 15 & No & In concave & Yes & $3 \mathrm{mo}$ \\
\hline Totally & $13(65)$ & 21 & $10-36$ & 3 & All in concave & All & $<1 \mathrm{yr}$ \\
\hline
\end{tabular}

\section{Discussion}

The goal of OO surgery is to remove the nidus entirely without causing pathologic fracture, especially facets and pedicles or disrupting the adjacent uninvolved tissues [25].

Surgical intra-lesional excision has been the commonly accepted treatment for a long time [26,27].

At present, laser photocoagulation and percutaneous radiofrequency coagulation techniques are more popular treatments for OO outside the spine [5].

Recently, micro endoscopic technique, percutaneous tunnel surgery and curettage using a navigation system have been described as minimally invasive treatments, which need steep learning curves, education and equipment $[5,25,28]$.

The average age of our patients was 19.8 years and the male to female ratio was about $3: 2(58 \%$ vs. $42 \%)$. These results are similar to other studies $[11,12]$. A review of literature showed OO located in the thoracic spine and particularly in the vertebral body to be uncommon [22].

Gasbarrini et al. [5] showed a little difference in distribution of pathologic levels in a study of 81 cases with 28 in the lumbar, 27 in the thoracic and 26 in the cervical regions.

Other studies indicate the thoracic region as the least and the lumbar as the most common locations [18].

Saifuddin et al. [29] reported that the thoracic and lumbar regions are the most common sites of involvement.

Our study showed the lumbar and thoracic involvements with similar distributions ( 7 and 7 of 19 cases) with T11 and (L3-L4) being the most prevalent locations. As mentioned in other studies $[3,11,12]$, we propose that the thoracolumbar and lumbar regions are the most common locations of involvement. Considering each vertebra, the most commonly affected location of involvement has been reported as the neural arch in $75 \%$ of cases with distributions of 33\% in the lamina, $20 \%$ in the articular facets and $15 \%$ involvement of the pedicle $[22,24]$. Gasbarrini et al.
[5] reported only $22 \%$ of cases in sectors 5-8 (equivalent to the body) and the greatest majority of cases were in sectors 2-4 and 9-11.

Our results showed that the most common locations of involvement were the lamina equivalent to sectors 2-4 (35\%) and 9-11 (60\%) of WBB classification.

In our study, there was more preponderance to involvement of the right side (60\%) versus the left side (35\%) and the rest were in the midline $(p=0.001)$. Also, pain was the most prominent complaint in our cases (84.2\%) with $62.5 \%$ of them reporting nocturnal exacerbation and sleep disturbance.

Only $37.5 \%$ of our cases had radicular pain, which is similar to other reports, but a study conducted by Pourfeizi et al. [30] reported that pain was not the most common complaint. In the other words, scoliosis was the most common complaint because $45 \%$ of their patients did not have severe enough pain to seek treatment.

The reported duration of pain is up to 68 months [5], but the average in several studies is about 15 to 20 months $[4,11,12]$. In our study duration of pain was from 4 to 56 months with an average of 15.1 months.

Considering this long period of time before accurate diagnosis, practitioners need to be aware of the possibility of $\mathrm{OO}$ in persistent and resistant cases of spinal pain especially when associated with deformity.

Spinal OO misdiagnosis is reported to be as high as $54.5 \%$ [30]. We only had one case of misdiagnosis and the patient underwent surgery three times to become pain free. Positive response to aspirin in our study was $43.7 \%$ (7 of 16 painful cases) but a range of $14 \%-90 \%$ has been reported [10-12].

Scoliosis especially the painful type, has been reported in $63 \%-70 \%$ of spinal OO $[22,23,26]$, which may not spontaneously resolve if the lesion is left for more than 9-15 months [14]. Although lesions have been reported to be in concave side of deformity in almost all cases including ours, Saifuddin et al. [29] reported 3 cases of 
convex side lesions. As shown in Table 6, there was spinal deformity in $65 \%$ of our cases (13 of 19 cases) and 12 of them $(60 \%)$ were scoliosis with an average of $21.5^{\circ}$ Cobb. In all of them, the lesions were on the concave side. Only 3 out of $12(25 \%)$ cases of patients with scoliosis had mild pain (VAS $\leq 3$ ).

All curves resolved and responded to primary surgery in an average of 8 months in scoliotic patients and 3 months for torticollis patient. A review of other studies shows that with modern surgical techniques, complete nidus resection was achieved in most $(>90 \%)$ cases $[2,12]$.

The reported recurrence rate of spinal OO is only $4.5 \%$ [3]-5\% [5]. We did not have any recurrence or neurologic deficit after surgical excision which is similar to many but not all of the previous studies [26].

Instability and fusion are issues that have been reported for $20 \%-50 \%$ of patients that underwent surgical OO excision [2], but Gasbarrini et al. [5] reported that only 5 of their 81 cases needed instrumentation and fusion. Fusion and instrumentation was done in 4 of our 19 cases (21\%).

Finally, an interesting finding in our study was a great relationship between spinal OO and one of our specific country races (Bakhtiari) with 10 of our 19 patients belonging to this population. This race lives in the high attitude Zagros Mountains. As far as we know, the role of race has not yet been mentioned in the literature.

Low number of cases in comparison with some other studies like Gasbarrini et al. [5], is one of our study limitations and this may be responsible for some of our results like tumor right sided predilection and no recurrences.

\section{Conclusions}

Surgical intra-lesional curettage is potentially an effective method without any recurrence, which can lead to spontaneous scoliosis recovery and pain relief. Race, may be a potential risk factor for spinal OO.

\section{Conflict of Interest}

No potential conflict of interest relevant to this article was reported.

\section{Acknowledgments}

We appreciate Professor Alireza Ebrahim Zadeh and Professor Majid Rezvani for their valuable cases sharing in our study.

\section{References}

1. Jaffe HL. "Osteoid-osteoma": a benign osteoblastic tumor composed of osteoid and atypical bone. Arch Surg 1935;31:709-28.

2. Kan P, Schmidt MH. Osteoid osteoma and osteoblastoma of the spine. Neurosurg Clin N Am 2008;19:6570.

3. Jackson RP, Reckling FW, Mants FA. Osteoid osteoma and osteoblastoma: similar histologic lesions with different natural histories. Clin Orthop Relat Res 1977;(128):303-13.

4. Marsh BW, Bonfiglio M, Brady LP, Enneking WF. Benign osteoblastoma: range of manifestations. J Bone Joint Surg Am 1975;57:1-9.

5. Gasbarrini A, Cappuccio M, Bandiera S, Amendola L, van Urk P, Boriani S. Osteoid osteoma of the mobile spine: surgical outcomes in 81 patients. Spine (Phila Pa 1976) 2011;36:2089-93.

6. Eck JC, DiPaola CP. Essentials of spinal disorders. New Delhi: Jaypee Brothers Medical Publishers; 2014.

7. Rodallec MH, Feydy A, Larousserie F, et al. Diagnostic imaging of solitary tumors of the spine: what to do and say. Radiographics 2008;28:1019-41.

8. Benzel EC. Spine surgery techniques, complication avoidance, and management. Philadelphia: Churchill Livingstone; 2005.

9. Etemadifar MR, Ebrahimzadeh AR, Karimian M. Osteoid osteoma of cervical spine in two adjacent vertebrae. J Res Med Sci 2005;10:319-21.

10. Nemoto O, Moser RP Jr, Van Dam BE, Aoki J, Gilkey FW. Osteoblastoma of the spine: a review of 75 cases. Spine (Phila Pa 1976) 1990;15:1272-80.

11. Azouz EM, Kozlowski K, Marton D, Sprague P, Zerhouni A, Asselah F. Osteoid osteoma and osteoblastoma of the spine in children: report of 22 cases with brief literature review. Pediatr Radiol 1986;16:25-31.

12. Zileli M, Cagli S, Basdemir G, Ersahin Y. Osteoid osteomas and osteoblastomas of the spine. Neurosurg Focus 2003;15:E5.

13. Ozaki T, Liljenqvist U, Hillmann A, et al. Osteoid osteoma and osteoblastoma of the spine: experiences with 22 patients. Clin Orthop Relat Res 2002;(397): 394-402. 
14. Akbarnia BA, Rooholamini SA. Scoliosis caused by benign osteoblastoma of the thoracic or lumbar spine. J Bone Joint Surg Am 1981;63:1146-55.

15. Fehring TK, Green NE. Negative radionuclide scan in osteoid osteoma: a case report. Clin Orthop Relat Res 1984;(185):245-9.

16. Even-Sapir E, Martin RH, Barnes DC, Pringle CR, Iles SE, Mitchell MJ. Role of SPECT in differentiating malignant from benign lesions in the lower thoracic and lumbar vertebrae. Radiology 1993;187:193-8.

17. Roach PJ, Schembri GP, Ho Shon IA, Bailey EA, Bailey DL. SPECT/CT imaging using a spiral CT scanner for anatomical localization: impact on diagnostic accuracy and reporter confidence in clinical practice. Nucl Med Commun 2006;27:977-87.

18. Kroon HM, Schurmans J. Osteoblastoma: clinical and radiologic findings in 98 new cases. Radiology 1990;175:783-90.

19. Cove JA, Taminiau AH, Obermann WR, Vanderschueren GM. Osteoid osteoma of the spine treated with percutaneous computed tomography-guided thermocoagulation. Spine (Phila Pa 1976) 2000; 25:1283-6.

20. Kransdorf MJ, Stull MA, Gilkey FW, Moser RP Jr. Osteoid osteoma. Radiographics 1991;11:671-96.

21. Kneisl JS, Simon MA. Medical management compared with operative treatment for osteoid-osteoma. J Bone Joint Surg Am 1992;74:179-85.

22. Hadjipavlou AG, Lander PH, Marchesi D, Katonis
PG, Gaitanis IN. Minimally invasive surgery for ablation of osteoid osteoma of the spine. Spine (Phila Pa 1976) 2003;28:E472-7.

23. Osti OL, Sebben R. High-frequency radio-wave ablation of osteoid osteoma in the lumbar spine. Eur Spine J 1998;7:422-5.

24. Wells RG, Miller JH, Sty JR. Scintigraphic patterns in osteoid osteoma and spondylolysis. Clin Nucl Med 1987;12:39-44.

25. Moore T, McLain RF. Image-guided surgery in resection of benign cervicothoracic spinal tumors: a report of two cases. Spine J 2005;5:109-14.

26. Pettine KA, Klassen RA. Osteoid-osteoma and osteoblastoma of the spine. J Bone Joint Surg Am 1986;68:354-61.

27. Fett HC Sr, Russo VP. Osteoid osteoma of a cervical vertebra; report of a case. J Bone Joint Surg Am 1959; 41:948-50.

28. Nagashima H, Nishi T, Yamane K, Tanida A. Case report: osteoid osteoma of the $\mathrm{C} 2$ pedicle: surgical technique using a navigation system. Clin Orthop Relat Res 2010;468:283-8.

29. Saifuddin A, White J, Sherazi Z, Shaikh MI, Natali C, Ransford AO. Osteoid osteoma and osteoblastoma of the spine: factors associated with the presence of scoliosis. Spine (Phila Pa 1976) 1998;23:47-53.

30. Pourfeizi HH, Tabrizi A, Bazavar M, Sales JG. Clinical findings and results of surgical resection of thoracolumbar osteoid osteoma. Asian Spine J 2014;8:150-5. 